\title{
Reseña de sentencias del Tribunal Constitucional sobre la Administración Local y Autonómica que aparecen publicadas en el B.O.E. durante el segundo semestre de 1992 (meses de julio a octubre)
}

\author{
Francisco Javier Fernández González \\ Seminario de Derecho Administrativo \\ Universidad de Oviedo
}

\begin{abstract}
SUMARIO: 1. FUENTES. LEYES ORGÁNICAS. 2. DERECHO COMUNITARIO EUROPEO. 3. EMPLEO PÚBLICO. 4. JURISDICCION CONTENCIOSO-ADMINISTRATIVA. 5. RECURSO DE AMPARO. CAUSAS DE INADMISIÓN. 6. ACTIVIDAD ADMINISTRATIVA DE FOMENTO. 7. DERECHO PÚBLICO DE LA ECONOMÍA: a) Agricultura y ganadería. b) Defensa de los consumidores y usuarios. c) Entidades de crédito.
\end{abstract}

\section{FUENTES. LEYES ORGÁNICAS}

I. Cuestión de inconstitucionalidad 363/1988 promovida por la Sala Segunda del Tribunal Supremo, sobre supuesta inconstitucionalidad del art. 10. párr. 3. ${ }^{\circ}$, de la Ley 39/1981, de 28 de octubre, reguladora del uso de la bandera nacional y de otras banderas y enseñas. El Tribunal entiende que el párrafo impugnado, en cuanto obliga a aplicar siempre en todos los supuestos, con independencia de la forma en que se haya cometido el delito, la pena de prisión mayor, es contrario al art. 81.1 de la CE por no tener el rango de Ley orgánica, ya que existe una reserva constitucional en favor de la Ley orgánica (art. 81.1 en relación con el art. 17.1 CE), respecto de las normas penales que establezcan penas privativas de libertad.

«El art. 10 de la citada Ley, en su párr. $3 .^{\circ}$, ahora cuestionado, establece lo siguiente:

"Los ultrajes y ofensas a las banderas a que se refiere el art. 3 de esta Ley, se consideran siempre como cometidas con publicidad a los efectos de lo dispuesto en el citado art. 123 del Código Penal".

Por su parte, el art. 123 del Código Penal dispone que: 
"Los ultrajes a la nación española o al sentimiento de su unidad, al Estado o su forma política, así como a sus símbolos y emblemas, se castigarán con la pena de prisión menor, y si tuvieren lugar con publicidad, con la de prisión mayor" (...).

Existe reserva constitucional en favor de la Ley orgánica, de conformidad con lo dispuesto en el art. 81.1, en relación con el art. 17.1 CE, respecto de las normas penales que establezcan penas privativas de libertad.

En efecto, el derecho a la libertad y seguridad consagrado en el art. 17.1 de la CE incluye todas las garantías previstas en otros preceptos constitucionales (arts. 25.1, 53.1 y 2, y 81.1) cuya vulneración supone la del mismo derecho. La remisión a la Ley que lleva a cabo el art. 17.1 de la CE ha de entenderse como remisión a la Ley orgánica, de manera que la imposición de una pena de privación de libertad prevista en una norma sin ese carácter constituye una vulneración de las garantías del derecho a la libertad y, por ello, una violación de ese derecho fundamental (...).

No es posible considerar que el art. 10 párr. $3 .^{\circ}$, de la Ley $39 / 1981$ sea un simple complemento del art. 123 del Código Penal, ni que estemos en presencia de un supuesto de remisión normativa en el que no es exigible la garantía de reserva de Ley orgánica prevista en el art. 81.1 de la $C E$, puesto que, en realidad, no se trata de la integración de una Ley orgánica (en este caso de una Ley preconstitucional: El Código Penal) por una Ley ordinaria (la Ley 39/1981). Por el contrario, el art. 10.3 de la Ley 39/1981 se remite al art. 123 del Código Penal para fijar la pena de los ultrajes y ofensas a la bandera de España, a cuyo uso y utilización se refiere el art. 3 de la citada Ley, considerándolos siempre cometidos con publicidad a efectos de determinar la pena a imponer. Es forzoso concluir, por ello, que el art. 10, párr. 3. ${ }^{\circ}$, de la Ley 39/1981, en cuanto obliga a aplicar siempre en todos los supuestos, con independencia de la forma en que se haya cometido el delito, la pena de prisión mayor, es contrario al art. 81.1 de la CE por no tener el rango de Ley orgánica y procede declarar su inconstitucionalidad. En este sentido, es claro que la agravación penal de los ultrajes y ofensas a la bandera de España en la forma que lo hace la Ley 39/1981, y cualquiera que sea la técnica legislativa utilizada para ello, exige el rango de Ley orgánica de conformidad con lo dispuesto en los arts. 81.1 y 17.1 de la Constitución» (vid. ff. jj. 1, 2 y 4).

FALLO: Estimar la cuestión de inconstitucionalidad y, en consecuencia, declarar inconstitucional y, por tanto, nulo, el párrafo impugnado.

(Sentencia n. ${ }^{\circ} 118 / 1992$, de 16 de septiembre. BOE 14-10-1992. L. López Guerra). 
JURISPRUDENCIA

II. Cuestión de inconstitucionalidad 175/1991, promovida por la Sección Quinta de la Audiencia Provincial de Valencia en relación con el art. 10.1 y 2, de la Ley 39/1981, de 28 de octubre, reguladora del uso de la bandera nacional y de otras banderas y enseñas. El Tribunal estima parcialmente la cuestión y declara inconstitucional el art. 10.2 de la Ley impugnada, puesto que como reforma por remisión de un precepto del Código Penal que impone una pena privativa de libertad, debería haber adoptado el rango de Ley Orgánica.

«El art. 10 de la citada Ley, en sus párrafos $1 .^{\circ}$ y $2 .^{\circ}$, ahora cuestionados, establece lo siguiente:

"1. Los ultrajes y ofensas a la bandera de España y a las contempladas en el art. 4 del presente texto se castigarán conforme a lo dispuesto en la Leyes.

2. Las infracciones de lo previsto en esta Ley se considerarán incursas en lo establecido en los arts. 123 y concordantes del Código Penal y, en su caso, en el art. 316 del Código de Justicia Militar, sin perjuicio de las sanciones administrativas que pudieran proceder" (...).

Siendo los principales símbolos de nuestro Estado la bandera de España y su escudo, también son símbolos del Estado español las banderas y enseñas previstas en el art. $4 \mathrm{CE}$ y reconocidas en los Estatutos de las CCAA, en tanto en cuanto éstas constituyen la expresión de la autonomía que la Constitución ampara y de la pluralidad y complejidad del Estado que configura (...) La Audiencia proponente ha estimado que el art. 123 del Código Penal, cuando habla de ultrajes a los símbolos y emblemas del Estado y de la Nación española, no le permite per se considerar punibles las ofensas que se puedan hacer a las banderas de las CCAA, y que dicha punición sólo le sería posible a partir del art. 10.1 y 2 de la Ley 39/1981 el cual no goza del carácter orgánico que le es exigible. Así pues nada se imputa al art. 123 del Código Penal ni al art. 10.1. y 2 desde el punto de vista de lo que cabe denominar requisitos sustantivos del principio de legalidad penal consagrado en el art. 25.1 CE. Ninguna duda cabe, por tanto, de que corresponde al legislador definir cuál es la protección penal que se debe brindar a la bandera de España y a las banderas autonómicas, así como que, en atención a lo que ha quedado expuesto, igualmente le corresponde decidir que todos esos símbolos del Estado español queden protegidos por un mismo tipo penal.

La única cuestión que se nos plantea es determinar si la técnica seguida por el legislador al aprobar la Ley 39/1981, y concretamente su art. 10.1 y 2 , respeta las exigencias formales del principio de legalidad 
penal y específicamente la reserva de Ley Orgánica que es exigible de conformidad con lo dispuesto en el art. 81.1 en relación con el art. 17.1, ambos de la CE, a las normas penales que establezcan penas privativas de libertad o restrictivas de otros derechos fundamentales (...).

El párrafo primero del art. 10 que la Ley 39/1981, aun cuando refleja una clara voluntad del legislador del Estado de equiparar la protección jurídica de las banderas de las CCAA a la de la bandera de España, lo cierto es que no contiene ningún mandato jurídico concreto, pues se limita a remitirse "a lo dispuesto en las leyes" respecto de las ofensas y ultrajes, modalidad de remisión normativa constitucionalmente válida por ser irrelevante desde la perspectiva penal, ya que no crea ningún tipo sino que se remite genéricamente a los eventuales tipos existentes, sin ordenar una ampliación de los mismos. Por ello ha de desestimarse la cuestión en relación con este párrafo primero.

Al contrario, el párrafo segundo del art. 10 de la Ley 39/1981 establece un mandato, el "considerar" incursos en los arts. 123 y concordantes del Código Penal "las infracciones de lo previsto en esta Ley". Para el órgano judicial y el Ministerio Fiscal, el precepto implica una extensión o ampliación del tipo, esto es, incluye conductas que hasta su aprobación no eran punibles...dicho con otras palabras, en vez de acudir a la vía directa de la reforma del Código Penal, el precepto opera una modificación de aquél, que sin integrarse en su texto, lo corrige a través de la remisión que la Ley cuestionada incluye.

Resulta evidente que así interpretado el precepto, como reforma por remisión de un precepto del Código Penal que impone una pena privativa de libertad, debería haber adoptado el rango de Ley Orgánica, y más aún teniendo en cuenta la incorrecta formulación abierta al tipo - "las infracciones de lo previsto en esta Ley"- que no cumple la exigencia constitucional de predeterminación normativa de la conducta penalmente ilícita, pues por el carácter genérico y extenso de la Ley, no es posible prever con suficiente seguridad la naturaleza y las características esenciales de las conductas constitutivas de la infracción penal tipificada (...).

El precepto cuestionado no viene a precisar o concretar los conceptos contenidos en el art. $123 \mathrm{CP}$, pues no se refiere en ningún momento a qué debe entenderse por símbolos o emblemas del Estado (lo que sí supondría una integración del art. $123 \mathrm{CP}$ del tipo de la que efectúa el propio art. 1 de la ley 39/1981), sino que se limita a determinar supuestos de aplicación de la pena prevista en el artículo penal mencionado, y a configurar, por tanto, y por sí misma, un tipo penal, que supone o pretende una extensión del contenido del art. $123 \mathrm{CE}$, lo que no podía hacer la Ley ordinaria" (vid. ff. jj. 1 y 2). 
JURISPRUDENCIA

FALLO: Estimar parcialmente la presente cuestión de inconstitucionalidad, y en su virtud declarar inconstitucional y, por tanto, nulo el art. 10, párrafo segundo, de la Ley 39/1981, de 28 de octubre.

(Sentencia $n .^{\circ} 119 / 1992$, de 18 de septiembre. BOE 14-10-1992. M. Rodriguez-Piñero y Bravo-Ferrer).

\section{DERECHO COMUNITARIO EUROPEO}

I. Requerimiento $1236 / 1992$ del Gobierno de la Nación acerca de la existencia o inexistencia de contradicción entre el artículo 13.2 de la Constitución Española y el art. $8 \mathrm{~B}$, ap. 1, del Tratado Constitutivo de la Comunidad Económica Europea en la redacción que resultaría del art. $G B, 10$, del Tratado de la Unión Europea. Incidencia en la extensión del derecho de sufragio pasivo de los no nacionales en las elecciones municipales, y necesidad de reforma de la Constitución.

"Tres son las normas constitucionales que pudieran incidir en la extensión del derecho de sufragio pasivo a los no nacionales en las elecciones municipales: El art. 13.2 que limita dicho derecho de participación política a los españoles, el art. 23 que reconoce el ejercicio de dicho derecho a los "ciudadanos" y el art. 1.2, en cuya virtud "la soberanía nacional reside en el pueblo español".

a) Mediante el art. $8 \mathrm{~B}$, ap. 1, que se incluirá en el Tratado Constitutivo de la CEE, se reconocerá a "todo ciudadano de la Unión" el derecho a ser elector y elegible en las elecciones municipales del Estado miembro del que no sea nacional, y en el que resida, "en las mismas condiciones - añade el precepto- que los nacionales de dicho Estado". Dicha previsión, junto a todas las demás contenidas en los distintos apartados del propio art. 8, viene a configurar una naciente ciudadanía europea que, sin abolir las distintas nacionalidades de los ciudadanos de los Estados signatarios del TUE...supone una parcial superación del tradicional binomio nacional/extranjero por vía de la creación de aquel tercer status común.

Es del todo claro, sin embargo, que esta limitada extensión del derecho de sufragio activo y pasivo, a quienes sin ser nacionales españoles son ciudadanos de la Unión encuentra un acomodo sólo parcial en las previsiones del art. 13 de nuestra Constitución, cuyo ap. 2 afirma que únicamente los españoles ostentan la titularidad de los derechos reconocidos en el art. 23 de la misma norma fundamental "salvo lo que, atendiendo a criterios de reciprocidad, pueda establecerse por tratado o Ley para el derecho de sufragio activo en las elecciones municipa-

\section{5}


les"...Por lo tanto, sin perjuicio de la citada salvedad contenida en el art. 13.2 en orden al sufragio activo en las elecciones municipales, y en virtud de estas reglas constitucionales no cabe, pues, ni por tratado ni por Ley, atribuir el derecho de sufragio pasivo a los no nacionales en cualquiera de los procedimientos electorales para la integración de órganos de los poderes públicos españoles.

La parcial contradicción así apreciable entre el repetido art. 13.2 de la Constitución y el texto sometido a nuestro examen habría de llevar, por consiguiente, a la conclusión de que dicho precepto contiene, en el extremo dicho, una estipulación que, por contraria a la Constitución, no podría ser objeto de ratificación sin la previa revisión de la norma fundamental, según dispone su art. 95.1.

b) El segundo de los preceptos enunciados en el que podría quizá apreciarse una colisión con el futuro art. $8 \mathrm{~B}, 1$, del TCCEE es el art. 23 y más concretamente su apartado segundo que, en forma de elipsis, confiere a los "ciudadanos" el derecho de acceder a los cargos públicos, en condiciones de igualdad, con los requisitos que señalan las leyes.

La redacción del precepto evidencia, sin embargo, en virtud de su remisión a la Ley, que la Constitución no consagra aquí un derecho a ocupar cargos y funciones públicas, sino simplemente la prohibición de que el legislador pueda regular el acceso a tales cargos y funciones en términos discriminatorios, pues, como repetidamente hemos afirmado, el precepto en cuestión es una concreción del principio general de igualdad.

En cuanto que la interdicción de la discriminación se refiere, según la letra del artículo, sólo a los ciudadanos, es obvio que del mismo no se deriva prohibición alguna, ni de que el derecho otorgado a éstos por las leyes se extienda también a quienes no lo son, ni que al prever el modo de acceso a cargos o funciones públicas determinadas se establezcan condiciones distintas para los ciudadanos y los que no lo son.

En relación con el sufragio pasivo, el art. 23.2 no contiene, por tanto, ninguna norma que excluya a los extranjeros del acceso a cargos y funciones públicas. En efecto, no es el art. 23 el precepto que en nuestra Constitución establece los límites subjetivos determinantes de la extensión de la titularidad de los derechos fundamentales a los no nacionales. En nuestra Constitución dicha norma, atinente a este requisito de la capacidad, no es el art. 23, sino el art. 13, en cuyo primer párrafo se procede a extender a los extranjeros el ejercicio de todas las libertades públicas reconocidas en el título I de la CE en los términos que establezcan los tratados y la Ley. Esta extensión se ve exceptuada por la cláusula del art. 13.2 que excluye de ella a determinados derechos reco- 
nocidos en el art. 23, restringidos, en consecuencia, únicamente a los españoles. Pero esa exclusión no deriva, por tanto, de las previsiones del art. 23, que por sí mismo no prohíbe que los derechos allí reconocidos puedan extenderse, por Ley o tratado, a los ciudadanos de la Unión Europea. No cabe, por tanto, estimar que la previsión del futuro art. 8.B, 1 del TUE contradiga el art. $23 \mathrm{CE}$, haciendo necesario recurrir al procedimiento del art. $168 \mathrm{CE}$.

c) Tampoco la proclamación inscrita en el art. 1.2 de la Constitución queda contradicha, ni afectada siquiera, por el reconocimiento del sufragio pasivo, en las elecciones municipales, a un determinado círculo o categoría de extranjeros. Sin entrar en otras consideraciones ahora ociosas, sea suficiente advertir, para fundamentar lo dicho, que la atribución a quienes no son nacionales del derecho de sufragio en elecciones a órganos representativos sólo podría ser controvertida, a la luz de aquel enunciado constitucional, si tales órganos fueran de aquéllos que ostentan potestades atribuidas directamente por la Constitución y los Estatutos de Autonomía y ligadas a la titularidad por el pueblo español de la soberanía. No tendría sentido alguno, como es obvio, formular ahora juicios hipotéticos, de modo que basta con advertir que ése no es el caso de los municipios, para descartar toda duda sobre la constitucionalidad, en cuanto a este extremo, de lo prevenido en la estipulación aquí examinada» (vid. f.j. 3).

"La conclusión que se impone es, pues, la de que existe una contradicción, irreductible por vía de interpretación, entre el art. $8 \mathrm{~B}$, ap. 1 del Tratado de la CEE, según quedaría el mismo redactado por el TUE, de una parte, y el art. 13.2 de nuestra Constitución, de otra; contradicción que afecta a la parte de aquel precepto que reconocería el derecho de sufragio pasivo en las elecciones municipales a un conjunto genérico de personas (los nacionales de otros países miembros de la Comunidad) que no tienen la condición de españoles. La única vía existente en Derecho para superar tal antinomia, y para ratificar o firmar aquel tratado, es, así, la que ha previsto la Constitución en su art. 95.1: La previa revisión de la Norma fundamental en la parte de la misma que impone hoy la conclusión de esta declaración. Dicha reforma constitucional habrá de remover el obstáculo contenido en el art. 13.2, que impide extender a los no nacionales el derecho de sufragio pasivo en las elecciones municipales.

De todo lo anteriormente expuesto se infiere la conclusión de que, al no contrariar el precepto examinado otra norma de la Constitución distinta al art. 13.2 de la misma, el procedimiento para la revisión constitucional, que prevé el art. 95.1 ha de ser el de carácter general u ordinario contemplado en el art. 167 de nuestra Ley fundamental» (vid. f.j. 6). 
FALLO: $1 .^{\circ}$ Que la estipulación contenida en el futuro art. $8 \mathrm{~B}$, ap. 1 , del Tratado Constitutivo de la Comunidad Económica Europea, tal y como quedará redactado por el Tratado de la Unión Europea, es contraria al art. 13.2 de la Constitución en lo relativo a la atribución del derecho de sufragio pasivo en elecciones municipales a los ciudadanos de la Unión Europea que no sean nacionales españoles.

$2 .^{\circ}$ Que el procedimiento de reforma constitucional, que debe seguirse para obtener la adecuación de dicha norma convencional a la Constitución, es el establecido en su art. 167.

(Declaración de 1 de julio de 1992 en relación con el art. 8 B, ap. 1, del Tratado Constitutivo de la Comunidad Económica Europea en la redacción que resultaría del art. GB, 10, del Tratado de la Unión Europea. BOE 24-7-1992. V. Gimeno Sendra).

\section{EMPLEO PÚBLICO}

I. Conflicto positivo de competencia 386/1986 promovido por el Consejo Ejecutivo de la Generalidad de Cataluña, en relación con el $R D$ 2253/1985, de 22 de mayo, sobre especialización en Derecho foral como mérito preferente para el nombramiento de Notarios en las Comunidades Autónomas de Aragón, Cataluña, Galicia y Navarra. El Tribunal declara que la competencia controvertida corresponde al Estado porque la regulación de los méritos en los concursos para provisión de Notarías entra en la competencia del Estado para regular el régimen de ingreso y provisión de aquéllas, dentro del régimen estatutario del Notariado.

"No puede aceptarse la alegación de que el RD impugnado sea una norma directamente orientada a la conservación y desarrollo del Derecho civil catalán mediante la práctica notarial...muy al contrario, el objeto y fin propio del Decreto es la regulación de un cierto mérito en los concursos para provisión de Notarías en el territorio de las CCAA que se cita, y por ello forma parte del Estatuto profesional de los Notarios, así como de su intervención en la formulación de los instrumentos públicos (...).

El RD objeto del presente conflicto (se desprende incluso de las alegaciones de la Generalidad al basar su pretensión en el art. 9,2 EAC) no regula una materia perteneciente a la competencia ejecutiva en materia de nombramiento de Notarios, pues, como su propio preámbulo indica, trata sólo de regular el mérito preferente previsto en diversos Estatutos de Autonomía. Por medio de este RD, el Estado ha ejercido una función normativa propia derivada del art. 24.1 del Estatuto de Catalu- 
JURISPRUDENCIA

ña, pues cuando éste establece que "los Notarios...serán nombrados por la Generalidad, de conformidad con las Leyes del Estado" entendiendo como corresponde la expresión, Ley del Estado en el sentido amplio de norma estatal, será del Estado la competencia para dictar el Reglamento controvertido.

Esta competencia reguladora, por otra parte, deriva también del carácter de funcionarios públicos del Estado que tienen los Notarios y su integración en un cuerpo único nacional (...)

De acuerdo con el reparto de competencias establecido por la Constitución y los Estatutos de Autonomía, no corresponde a la Generalidad de Cataluña la regulación de la especialización en Derecho catalán como mérito preferente para la provisión de Notarías en Cataluña, porque ello entra en la competencia del Estado para regular el régimen de ingreso y provisión de aquéllas, dentro del régimen estatutario del Notariado. La competencia sobre la materia justifica que sea el ejecutivo estatal el competente para regular el mérito preferente objeto del RD impugnado, que, como condición general, afecta a todos los Notarios por igual...y, por lo tanto, no se inserta en la competencia que en materia de nombramiento de Notarios el art. 24.1 del EAC atribuye a la Generalidad de Cataluña" (vid. ff. jj. 3 y 4 ).

FALLO: Desestimar la pretensión de la demandante y declarar que la titularidad de la competencia controvertida en el presente conflicto corresponde al Estado.

(Sentencia n. ${ }^{\circ}$ 120/1992, de 21 de septiembre. BOE 14-10-1992. J. Gabaldón López. Voto particular que formulan L. López Guerra, V. Gimeno Sendra y $C$. Viver Pi-Sunyer).

\section{JURISDICCIÓN CONTENCIOSO-ADMINISTRATIVA}

I. Recurso de amparo 402/1989 interpuesto por el Gobierno de Navarra contra once Autos de la Sala de lo Contencioso-Administrativo de la Audiencia Territorial de Pamplona, dictados en los días 14 a 26 de enero de 1989, así como contra once Autos de la misma Sala de 7 y 9 de febrero de 1989, desestimatorios de recursos de súplica contra los anteriores, recaidos todos ellos en incidente de ejecución de Sentencia de 22 de enero de 1987 relativa a una cuestión de personal sobre asignación de grado y antigüedad a funcionarios del Gobierno de Navarra. El Tribunal entiende que se ha producido una vulneración del derecho fundamental a obtener la tutela efectiva de Jueces y Tribunal, puesto que al extender los efectos del fallo de una Sentencia mediante el trámite de ejecución a una serie de 
funcionarios que lo habian solicitado sin haber sido parte en el proceso, el recurso de apelación en interés de la Ley interpuesto frente a dicha Sentencia por los demandantes de amparo, pierde su finalidad y su utilidad real, lo que no resulta compatible con el art. 24.1 CE.

«El derecho a utilizar los recursos legalmente previstos contra las decisiones judiciales forma parte del derecho constitucional a la tutela judicial efectiva. Es evidente también que ese derecho se refiere tanto a los recursos ordinarios como a los extraordinarios...Naturalmente, este derecho a los recursos y los correlativos deberes judiciales no se limitan a la mera interposición de aquéllos. Dado que la tutela judicial que el art. 24.1 CE garantiza no es meramente teórica o formal, sino efectiva, el derecho a los recursos conlleva también el derecho a la utilidad o efectividad de los recursos legalmente previstos e interpuestos, de manera que no pueden los órganos judiciales privar injustificadamente de su utilidad a un recurso ya formulado y admitido, de manera directa o indirecta.

Entre los recursos judiciales a que alcanza el referido derecho no cabe excluir el recurso extraordinario de apelación en interés de la ley, previsto en su día por el art. 101 de la Ley de la Jurisdicción Contencioso-Administrativa (hoy por el art. 102.b de la misma Ley), en favor de las entidades o sujetos públicos legitimados para interponerlo. Este recurso tenía y tiene por finalidad permitir que se corrijan las resoluciones de los Tribunales de aquella jurisdicción (salvo el Tribunal Supremo) que se estiman "gravemente dañosas y erróneas", de tal manera que el Tribunal Supremo pueda fijar, en su caso, una doctrina legal correctora, pero respetando "la situación jurídica particular derivada del fallo impugnado". Como es lógico, la razón de ser o la utilidad de este tipo de recurso consiste en posibilitar que la doctrina o fundamentación de la resolución impugnada, que se considera gravemente dañosa y errónea, no se aplique, de ser declarada como tal, a situaciones similares a las enjuiciadas por aquélla. Desde el momento en que los efectos del fallo recurrido se extienden por vía de ejecución a cualquier persona que, encontrándose en similar situación a la de los que forman parte en el proceso, lo solicite, y desde el momento en que por esta vía puedan crearse nuevas (y múltiples) situaciones jurídicas individualizadas derivadas del fallo, es claro que el recurso de apelación en interés de la Ley que se haya interpuesto pierde su finalidad intrínseca y su utilidad propia, para convertirse en un recurso puramente teórico.

Esto es precisamente lo que ha venido a suceder en el caso que contemplamos. La Sentencia que fue recurrida en interés de la Ley por el Gobierno de Navarra y el Abogado del Estado reconocía una situación jurídica individualizada en favor de ocho funcionarios, situación que 
ya no podía ser modificada en virtud de aquel recurso. Pero mediante éste se pretendía, desde luego, de acuerdo con su naturaleza, modificar una doctrina legal que se estimaba gravemente dañosa y de la que podrían beneficiarse otros muchos funcionarios en detrimento de la $\mathrm{Ha}$ cienda Foral. La extensión directa de los efectos del fallo, mediante el trámite de ejecución a varios cientos de esos funcionarios, reconociéndoles las correspondientes situaciones jurídicas individuales venía a privar al recurso formulado en interés de la Ley de toda utilidad real o, al menos, a mermar muy considerablemente su eficacia, consecuencia esta no compatible con el art. 24.1 CE.

La Sala de Pamplona, conocedora de que se había interpuesto contra su Sentencia de 22 de enero de 1987 un recurso de apelación en interés de la Ley, que ella misma había admitido unos meses antes, debió tenerlo en cuenta al interpretar y aplicar el art. 86.2 de la Ley Jurisdiccional, a efectos de resolver sobre la inserción en el trámite de ejecución de la Sentencia de los funcionarios que lo habían solicitado sin haber sido parte en el proceso. Al no hacerlo así, limitó o anuló sustancialmente el derecho de la demandante de amparo a los recursos legalmente previstos, que forman parte de su derecho fundamental a la tutela judicial efectiva, conclusión que es confirmada por el sentido de la STS en interés de la Ley recaída el 24 de enero de 1990» (vid. f.j. 4).

FALLO: Estimar el recurso de amparo y, en consecuencia:

1. ${ }^{\circ}$ Anular los Autos impugnados.

2..$^{\circ}$ Reconocer al Gobierno de Navarra su derecho a la tutela judicial efectiva en el proceso en que se dictaron dichos Autos, incluido el derecho a los recursos.

(Sentencia $n .^{\circ} 111 / 1992$, de 14 de septiembre. BOE 14-10-1992. C. de la Vega Benayas).

II. Recurso de inconstitucionalidad 361/1987, promovido por el Gobierno de la Nación, contra los arts. 2, párrafo segundo; último inciso del art. 3.2; art. 9 y disposición transitoria de la Ley 6/1986, de 15 de diciembre, de la Generalidad Valenciana, de Regulación de los Arrendamientos Históricos Valencianos. De las particularidades del régimen sustantivo y de la especificidad del arrendamiento histórico valenciano no deriva ninguna necesaria especialidad de la ordenación de las vías procesales, de modo que la competencia autonómica para legislar sobre estos arrendamientos no conlleva una competencia legislativa de carácter procesal para establecer una regulación singular de ordenación del proceso. 
«La impugnación de los arts. 2, segundo párrafo, y 3.2, último inciso, tiene en el recurso una misma motivación. Para el Abogado del Estado, tanto el primero de estos preceptos (según el cual la declaración de reconocimiento de los arrendamientos históricos "podrá ser impugnada ante la jurisdicción contencioso-administrativa por aquélla de las partes que considere lesionados sus derechos o intereses") como la referencia final del art. 3.2 ("La resolución recaída podrá también ser objeto de impugnación en vía administrativa") conculcan la exclusiva competencia del Estado ex art. 149.1.6 CE en orden a la legislación procesal, pues una y otra de estas previsiones - se viene a decir en el recurso- alteran el régimen de distribución de competencias diseñado en la LOPJ, ya que la controversia sobre la existencia de los arrendamientos históricos debiera sustanciarse ante el Juez civil. La representación de la Generalidad, por su parte, ha defendido la validez de estas reglas haciendo notar que las mismas no contrariarían aquella intervención del Juez civil, pues las referencias a la jurisdicción contencioso-administrativa habrían de entenderse en relación con los posibles vicios de que estuviera aquejado, en hipótesis, el acto administrativo de "reconocimiento" del arrendamiento histórico (...)

La atribución por la Constitución de competencia exclusiva al Estado en punto a la legislación procesal lo es "sin perjuicio de las necesarias especialidades que en este orden se deriven de las particularidades del derecho sustantivo de las CCAA" (art. 149.1.6) salvedad, ésta última, que ha dado lugar a la competencia atribuida en el art. 31.1 del EACV y sobre las que ha tenido ya ocasión de pronunciarse este Tribunal...con la expresión "necesarias especialidades" la Constitución tiene en cuenta tan sólo las que inevitablemente se deduzcan, desde el punto de vista de la defensa judicial, de las reclamaciones jurídicas sustantivas configuradas por la norma autonómica en virtud de las particularidades del derecho creado por la propia Comunidad... Desde luego, de las particularidades del régimen sustantivo y de la especificidad del arrendamiento histórico valenciano no deriva ninguna necesaria especialidad de la ordenación de las vías procesales y de la defensa judicial de los derechos y deberes derivados de esa relación arrendaticia, de manera que la competencia autonómica para legislar sobre estos arrendamientos no conlleva una competencia legislativa de carácter procesal para establecer una regulación singular de ordenación del proceso.

A ello ha de añadirse que el art. 2 de la Ley 6/1986 no establece una particularidad en la ordenación del proceso, sino una regla de competencia jurisdiccional cuya determinación corresponde en exclusiva al legislador estatal, y más concretamente a la LOPJ (art. 122.1 CE), y normas concordantes, que han delimitado ya la competencia en el orden civil de los juzgados y Tribunales en materia contractual en las controversias entre partes en materia de contratos privados. El legisla- 
dor autonómico en ningún caso puede interferirse en dicho orden competencial o perturbarlo, pero esto es lo que venido a hacer con una norma que no puede ser entendida sino como excluyente de la intervención que, según la legislación aplicable, han de tener aquí los órganos jurisdiccionales civiles para resolver las controversias que surjan en torno a la calificación y régimen jurídico de estos contratos.

Por todo ello, resulta evidente la inconstitucionalidad del art. 2 párrafo segundo, de la Ley valenciana 6/1986.

Por iguales razones a las hechas valer frente al segundo párrafo del art. 2 se ha impugnado también en el recurso el inciso final del art. 3.2. Es evidente, en efecto, la estrecha conexión existente entre ambas previsiones legales, hasta el extremo de que la contenida en el referido art. 3.2 parece mera reiteración, defectuosamente redactada, de la contenida, al efecto, en el examinado art. 2 (aunque la expresión "vía administrativa" podría hacer pensar, y así lo entiende la Abogacía del Estado, en los recursos administrativos previos a la vía contenciosa, mas parece que esta mención legal alude, sencillamente, a dicha vía jurisdiccional, pues de lo contrario no se entendería el adverbio "también" que se introduce en la disposición). En todo caso, la disposición ha de ser declarada inconstitucional por las mismas razones que se acaban de exponer a propósito del ya examinado art. 2, esto es, no por la ilegitimidad constitucional de su contenido material, sino por lo que el precepto expresa de intento de ordenación en este campo, de las vías jurisdiccionales a través de las que controvertir el reconocimiento de arrendamiento histórico. Dicha ordenación -importa reiterarlo- no puede ser emprendida por el legislador autonómico" (vid. f.j. 4).

FALLO: $1 .^{\circ}$ Declarar la inconstitucionalidad y consiguiente nulidad del art. 2, párrafo segundo, y del inciso final («la resolución recaída podrá también ser objeto de impugnación en vía administrativa") del art. 3.2 de la Ley impugnada.

$2{ }^{\circ}$ Rechazar, en todo lo demás, el recurso de inconstitucionalidad.

(Sentencia $n .^{\circ} 121 / 1992$, de 28 de septiembre. BOE 29-10-1992. M. Rodriguez-Piñero y Bravo-Ferrer. Votos particulares formulados por C. de la Vega Benayas y J. Gabaldón López).

\section{RECURSO DE AMPARO. CAUSAS DE INADMISIÓN}

I. Recurso de amparo 88/1989 formulado contra Sentencia de la Sala de lo Social del Tribunal Supremo, de 18 de mayo de 1988, que confirmó la Sentencia de la Magistratura de Trabajo $n .^{\circ} 6$ de Vizcaya, de 10 de fe- 
brero de 1987, en asunto sobre despido improcedente de trabajador del Ayuntamiento de Erandio. Extemporaneidad de la demanda, pues el plazo del art. 44.2 LOTC ha de comenzar a contarse desde el momento en que se produjo la notificación a la representante del recurrente y no desde el posterior en que se produjo la notificación directa al interesado.

"Con carácter previo, es preciso analizar la causa de inadmisión puesta por la representación del Ayuntamiento de Erandio. Para dicha Corporación Local, la demanda de amparo ha sido interpuesta fuera del plazo de 20 días establecido en el art. 44.2 LOTC, puesto que, aunque la demanda se presentara cuando todavía no habían transcurrido 20 días desde la notificación de la Sentencia dictada por la Sala de lo Social del Tribunal Supremo por la Magistratura de Trabajo núm. 6 de Vizcaya, dicha Sentencia había sido notificada con anterioridad por el propio Tribunal Supremo, según se desprende de las actuaciones correspondientes al recurso de casación.

La afirmación que hace la parte recurrida es cierta. Consta, en efecto, en las actuaciones remitidas por el Tribunal Supremo que el escrito de preparación del recurso de casación fue presentado en nombre y representación del ahora recurrente...En este escrito se fijó a efectos de notificaciones un domicilio en Madrid. Y a este domicilio se remitió la notificación postal de la Sentencia dictada por el Tribunal Supremo que fue efectivamente recibida, según se desprende del acuse de recibo, el 21 de octubre de 1988. Con posterioridad, una vez devueltas las actuaciones a la Magistratura, ésta procedió a notificar la Sentencia del Tribunal Supremo en el domicilio que el ahora recurrente había fijado en el escrito de demanda. Esta segunda notificación se recibió, según consta en el correspondiente acuse, el 22 de diciembre de 1988. La demanda de amparo, en fin, se presentó en este Tribunal el 13 de enero de 1989.

A la vista de estos datos, es preciso concluir que la demanda es extemporánea, pues el plazo del art. 44.2 LOTC ha de empezar a contarse desde el momento en que se produjo la notificación a la representante del recurrente y no desde el posterior en que se produjo la notificación directa al interesado. Así ha de concluirse a la vista de reiterada doctrina de este Tribunal que, en supuestos análogos, ha considerado que la notificación realizada al representante del interesado surte plenos efectos y, por tanto abre el plazo para interponer la demanda de amparo, con independencia de la existencia o no de notificación personal al interesado y del momento en que ésta se produzca» (vid. f. j. 1).

FALLO: Denegar el amparo solicitado.

(Sentencia $n^{\circ}$ 122/1992, de 28 de septiembre. BOE 29-10-1992. V. Gimeno Sendra). 
JURISPRUDENCIA

\section{ACTIVIDAD ADMINISTRATIVA DE FOMENTO}

I. Recursos de inconstitucionalidad 809 y 825/1986 (acumulados) promovidos por el Consejo Ejecutivo de la Generalidad de Cataluña y por el Presidente del Parlamento de Cataluña, respectivamente, contra determinados artículos de la Ley 13/1986, de 14 de abril, de Fomento y Coordinación General de la Investigación Científica y Técnica. El Tribunal desestima los recursos por entender que no se invaden competencias autonómicas.

«La competencia estatal en la materia de investigación científica y técnica no queda ceñida o limitada a la coordinación general de la actividad resultante del ejercicio de las competencias autonómicas en la referida materia, sino que alcanza, asimismo, al fomento de la investigación científica y técnica. No obstante, la determinación del contenido y extensión de dicha competencia constituye la clave que permitirá dar respuesta adecuada a buena parte de las impugnaciones efectuadas, razón por la cual es preciso puntualizar sobre dicha competencia lo siguiente:

a) Existe un pleno paralelismo entre el art. 149.1.15 de la CE y el art. 148.1.17 a de la CE que reconoce a las Comunidades Autónomas la posibilidad de asumir estatutariamente competencias -como así ha sucedido en líneas generales, aunque con cierta heterogeneidad en las fórmulas utilizadas - en la materia "fomento (...) de la investigación" lo que evidencia que, constitucionalmente, la misma materia queda o puede quedar, en principio, a la plena disponibilidad de una pluralidad de Centros decisores, es decir, a la disponibilidad del Estado y a la de todas las Comunidades Autónomas.

b) No resulta en absoluto convincente la tesis de que el fomento de la investigación científica y técnica, dado su contenido, circunscriba la competencia estatal - y, en su caso la autonómica- al mero apoyo estímulo o incentivo de las actividades investigadoras privadas a través de la previsión y otorgamiento de ayudas económicas o de recompensas honoríficas y similares, excluyendo, como contrapuesta, aquellas otras acciones directas de intervención consistentes en la creación y dotación de Centros y organismos públicos en los que se realicen actividades investigadoras, sino que la señalada expresión engloba a todas aquellas medidas encauzadas a la promoción y avance de la investigación, entre las que, sin duda, deben también incluirse las de carácter organizativo y servicial que permitan al titular de la competencia crear y mantener unidades y Centros dedicados al desarrollo y divulgación de las tareas investigadoras. 
c) $\mathrm{Al}$ atribuirse constitucionalmente al Estado la competencia para el fomento de la actividad investigadora y científica, tampoco cabe duda de que el titular de la competencia asume potestades, tanto de orden normativo como ejecutivo, para el pleno desarrollo de la actividad de fomento y promoción...

d) Finalmente, la competencia relativa al fomento de la investigación científica y técnica es proyectable sobre cualquier sector material, sin que, por tanto, considerando la investigación como contenido inherente a la competencia exclusiva sobre determinada materia, pueda pretenderse la exclusión del ejercicio de la competencia para el fomento de la investigación en los ámbitos materiales cuya titularidad no corresponde a quien ejercita dicha competencia (...).

La competencia autonómica queda situada en pleno paralelismo sustancial con la atribuida al Estado, de manera que la actividad que éste despliega no puede impedir ni interferir —dejando al margen, claro es, los efectos anudados a la competencia estatal de coordinación general- la que decida desarrollar la CA, al haber optado la CE en este ámbito...por posibilitar un régimen competencial en términos de concurrencia, que en el caso de la CA de Cataluña se ha hecho plenamente efectivo" (vid. f. j. 2).

FALLO: Desestimar los recursos de inconstitucionalidad.

(Sentencia n. ${ }^{\circ}$ 90/1992, de 11 de junio. BOE 15-7-1992. C. de la Vega Benayas).

\section{DERECHO PÚBLICO DE LA ECONOMÍA:}

\section{a) Agricultura y ganadería}

I. Conflicto positivo de competencia 1595/1987, planteado por el Consejo Ejecutivo de la Generalidad de Cataluña, frente al apartado sexto, último párrafo, y al apartado octavo de la Resolución de la Dirección General de Producción Agraria del Ministerio de Agricultura, Pesca y Alimentación, de 24 de julio de 1987, por la que se dictan normas sobre ayudas a la utilización de semillas controladas oficialmente. El Tribunal declara que las competencias controvertidas corresponden a la Generalidad de Cataluña.

«En materia de agricultura, que es de la competencia específica de las CCAA y por lo que aquí interesa, de Cataluña (art. 12.1.4 del EAC), el Estado sólo puede intervenir en virtud de sus competencias genera- 
les sobre la ordenación general de la economía. Esto significa que el Estado puede regular las condiciones de otorgamiento de las ayudas hasta donde lo permita su competencia genérica, básica o de coordinación, pero siempre que deje un margen a las CCAA, al menos para desarrollar y complementar la regulación de las condiciones de otorgamiento de las ayudas y su tramitación. En cuanto a las actividades de gestión o ejecución de las medidas de ayuda referidas —que es el aspecto que aquí importa-, deben corresponder por regla general a las CCAA con competencia en la materia, incluidas las actividades de verificación y control del cumplimiento de las condiciones a que se someta el otorgamiento de las ayudas por parte de sus beneficiarios. Esta regla sólo puede ser excepcionada cuando la gestión centralizada por un órgano de la Administración del Estado u organismo de ésta dependiente resulte imprescindible para asegurar la plena efectividad de las ayudas dentro de la ordenación básica del sector y para garantizar las mismas posibilidades de obtención o disfrute por parte de sus potenciales destinatarios en todo el territorio nacional, evitando al propio tiempo que se sobrepase la cuantía global de los fondos destinados al sector (...).

Según el apartado sexto, último párrafo, "para el pago del importe de las semillas a los productores por las Entidades financieras se entregará al solicitante un documento que sólo podrá ser hecho efectivo, previo visado por el Instituto Nacional de Semillas y Plantas de Vivero, por el productor de semillas que haya suscrito el contrato de compraventa". Es esta facultad de visado atribuida al referido Instituto Nacional al que la Generalidad considera que afecta a su competencia (...) Puede ser que, como el Abogado del Estado señala, mediante el visado en cuestión se pretenda también y al mismo tiempo evitar que se sobrepase la cuantía global de los fondos destinados al sector. Y si ésta fuera la única finalidad del visado...la competencia o el control del INSPV para realizarlo sería correcta y no invadiría las competencias de la Generalidad de Cataluña; pero lo cierto es que, como el propio Abogado del Estado señala en sus alegaciones, dicho visado cumple también y principalmente la finalidad "de que no se planteen actuaciones irregulares" y es aquí donde se produce la extralimitación o invasión de la competencia de la CA porque no sería lícito menoscabar, mediante este expediente del visado, la competencia ejecutiva de certificación y control de semillas controladas que corresponde a la Generalidad en su territorio. De ahí que no esté justificado reservar la citada facultad de visado al Instituto Nacional de Semillas y Plantas de Vivero (...).

También impugna la Generalidad el apartado octavo de la Resolución de 24 de julio 1987, según el cual, "en caso de incumplimiento de las normas establecidas en la Orden de referencia (la Orden comunicada de 20 de julio 1987) y en esta Resolución, así como en las normas de 
calidad de las semillas que figuran en las disposiciones legales vigentes, por el Instituto Nacional de Semillas y Plantas de Vivero se incoará el correspondiente expediente, pudiéndose sancionar a los productores de semillas con pérdida de la facultad de acogerse a lo dispuesto en la presente Resolución y, en su caso, comunicando el correspondiente tanto de culpa a la autoridad judicial" (...) Si se tiene en cuenta que, como el Abogado del Estado reconoce, a la Generalidad corresponde la competencia de certificación de semillas controladas oficialmente en dicho ámbito comercial, es evidente que la potestad sancionadora por incumplimiento de la normativa aplicable en esta materia ha de corresponder también a la Generalidad de Cataluña en el mismo ámbito" (vid. ff. jj. 1, 2 y 3).

FALLO: Declarar que la titularidad de las competencias controvertidas corresponde a la Generalidad de Cataluña.

(Sentencia n. ${ }^{\circ}$ 91/1992, de 11 de junio. BOE 15-7-1992. F. GarcíaMon y González-Regueral).

II. Conflicto positivo de competencia 793/1987 planteado por la Generalidad de Cataluña sobre los artículos $30^{\circ}$ y $7 .^{\circ}$ de la Orden del Ministerio de Agricultura, Pesca y Alimentación, de 29 de enero de 1987, por la que se instrumentan las ayudas para la compra de mantequilla por Instituciones y colectividades sin fines lucrativos. El Tribunal declara que admitida por el Gobierno la competencia de la Generalidad, el art. $3 .^{\circ}$ de la Orden impugnada, así modificada, no invade las competencias de dicha $C A$. Por otro lado, indica que corresponde a la Generalidad la competencia para recibir las solicitudes de ayuda y llevar a cabo el acto de pago respecto de las operaciones de compra realizadas por Instituciones y colectividades beneficiarias ubicadas en Cataluña.

«De acuerdo con el Reglamento CEE 2191/1981 (art. 1.3), los Estados miembros deben "autorizar" a todo "suministrador", ya sea envasador o importador, que pretenda beneficiarse de la ayuda a la compra de mantequilla que se realice por Entidades sin fines de lucro con sede en su territorio....No se trata de una "autorización" por operación que deba concederse o renovarse en cada venta de mantequilla, sino una autorización general y previa que habilita a ciertos suministradores para proceder a la venta subvencionada mientras esa autorización no les sea retirada por incumplimiento de las normas del Reglamento. Siendo así, está plenamente justificado que la competencia autorizadora, en relación con aquellos suministradores que operan en el territorio de más de una CA, corresponda al Estado. Sólo el Estado puede asegurar, para ellos, la posibilidad de operar en todo el territorio nacional benefi- 
JURISPRUDENCIA

ciándose de las ayudas. De lo contrario, los suministradores deberían ser autorizados o habilitados en todas y cada una de las CCAA en que operasen...Admitida por el Gobierno la competencia de la Generalidad para autorizar a los suministradores que operan únicamente en Cataluña, el art. $3 .^{\circ}$ de la Orden objeto de conflicto, así modificada, no invade las competencias de dicha CA.

Por lo que atañe al procedimiento para el otorgamiento y pago de ayuda, el Reglamento CEE 2191/1981 prevé (art. 3) que los suministradores de la mantequilla deben solicitar la ayuda por escrito y contra presentación de un bono numerado expedido por la autoridad competente del Estado miembro. Este bono se expide previo compromiso del destinatario de la mantequilla vendida de no utilizarla para fines distintos de los previstos en el Reglamento y previa certificación de la compra por parte del propio destinatario, entre otros requisitos, tendentes todos a garantizar el cumplimiento de las condiciones a las que la ayuda se sujeta. Una vez completo el expediente, procede el pago de la ayuda por la "autoridad competente" (art. 3.8)...La actividad administrativa de recepción (y lógicamente, tramitación y resolución), de las solicitudes del pago de la ayuda, al contrario que la autorización de la ayuda a los suministradores, se realiza separadamente por cada operación de compra de mantequilla o, al menos, por cada suministro a un mismo destinatario durante el período de vigencia de cada bono, como se deduce del art. $3 .^{\circ}$ del Reglamento CEE 2191/1981. Por consiguiente, si los bonos se expiden por la Generalidad de Cataluña en favor de los beneficiarios ubicados en su territorio, no hay razón alguna que justifique la gestión centralizada del expediente de solicitud del pago de la ayuda en relación con las operaciones de compra de mantequilla que se realicen en el territorio de la CA, incluso si el suministrador efectúa también otras operaciones fuera de ese territorio...No existiendo, pues, razón alguna que justifique la recepción de las solicitudes de ayuda por un organismo centralizado en el caso de aquellas operaciones de compra efectuadas por Entidades situadas en Cataluña, debe seguirse la regla general, reconociendo a la Generalidad la competencia correspondiente en estos casos (...).

El Derecho europeo no prejuzga si el pago de las ayudas del FEOGA, Sección Garantía, ha de realizarse en cada Estado miembro por un solo órgano u organismo centralizado o por varios en régimen de descentralización, como se desprende del art. 4.1 de Reglamento CEE $729 / 1970$...Sólo en aquellos casos en que corresponde a un órgano u organismo centralizado del Estado la resolución de los expedientes de solicitud de las ayudas..., resulta justificada la centralización de las operaciones de pago. En los demás casos, hay que entender que el acto de pago de las ayudas es un acto de ejecución que, conforme a las reglas 
generales antes expuestas, debe corresponder en principio a las CCAA con competencia en la materia. Por consiguiente, el Estado debe poner a disposición de los servicios u organismos competentes de las CCAA los fondos necesarios para el pago de las ayudas, librándolos en el momento y en la cuantía que sea procedente para que aquellos servicios u organismos las abonen a sus beneficiarios. Todo ello sin perjuicio del deber de las CCAA de facilitar al Estado los datos, documentos e informaciones precisas para que pueda cumplir las obligaciones que le impone el Derecho derivado europeo...y, naturalmente, sin merma de la sujeción de los propios servicios u organismos pagadores al Derecho europeo y a los controles y responsabilidades que se deriven.

En consecuencia, hay que concluir que las actividades de pago a que se refiere el art. 7. ${ }^{\circ}$ de la Orden de 29 de enero de 1987, objeto del conflicto, competen a la Generalidad de Cataluña en aquellos casos en que, como dice ahora el precepto, le corresponde la recepción y tramitación de las solicitudes, es decir, en relación con las operaciones de compra de mantequilla por instituciones y colectividades sin fines de lucro radicadas en Cataluña, en los términos del Reglamento CEE 2191/1981» (vid. ff. jj. 3,4 y 5).

FALLO: $10^{\circ}$ Que el art. $3 .^{\circ}$ de la Orden impugnada no invade competencias de la Generalidad de Cataluña.

2. ${ }^{\circ}$ Que corresponde a la Generalidad de Cataluña la competencia para recibir las solicitudes de ayuda y otorgar su pago, a que se refiere el art. $7 .^{\circ}$ de la citada Orden, respecto de las operaciones de compra de mantequilla realizadas por instituciones y colectividades beneficiarias ubicadas en Cataluña.

(Sentencia n. ${ }^{\circ} 117 / 1992$, de 16 de septiembre, BOE 14-10-1992. F. García-Mon y González-Regueral. Voto particular discrepante formulado por J. González Campos).

\section{b) Defensa de los consumidores y usuarios}

I. Conflicto positivo de competencia 785/1985 promovido por el Consejo Ejecutivo de la Generalidad de Cataluña contra los núms. $1 .^{\circ}$ y $3 .^{\circ}$ a $7 .^{\circ}$ de la Orden del Ministerio de Sanidad y Consumo de 29 de marzo de 1985, por la que se establecen normas para la concesión durante 1985 de subvenciones a las Asociaciones de Consumidores. No vulnera las competencias autonómicas la necesidad de la inscripción de las Asociaciones de Consumidores y Usuarios en el censo del Instituto Nacional de Consumo; pero sí vulnera las competencias autonómicas la regulación por el 
JURISPRUDENCLA

Estado de las finalidades específicas a que deben ir destinadas las subvenciones, asi como los requisitos y demás circunstancias sobre su otorgamiento y la gestión de las mismas.

«Dentro de la materia de defensa del consumidor y del usuario, la competencia sobre las Asociaciones de los Consumidores y Usuarios radicadas en la C.A. de Cataluña, que es la que nos interesa para resolver el presente conflicto, es competencia exclusiva de la citada Comunidad (...) Por consiguiente, cuando en el caso que nos ocupa nos encontramos ante una materia en la que tiene competencia exclusiva la C.A. de Cataluña, el Estado puede, desde luego, decidir asignar parte de sus fondos presupuestarios a la materia en cuestión, pero “...la determinación del destino de las partidas presupuestarias correspondientes no puede hacerse sino de manera genérica o global, por sectores o subsectores enteros de la actividad" (STC 13/1992). Por otra parte, en estos supuestos, la regulación del procedimiento para otorgar las subvenciones corresponde a la C.A. (STC 201/1988)" (vid. ff. jj. 4 y 5).

"Teniendo en cuenta la anterior doctrina, pasamos a analizar si los preceptos impugnados de la Orden ministerial suponen una invasión de la competencia exclusiva que ostenta la C.A. de Cataluña sobre las Asociaciones de Consumidores y Usuarios radicadas en su territorio, por parte de la Administración Central.

El núm. $1 .^{\circ}$ hace referencia a la necesidad de la inscripción de las Asociaciones de Consumidores y Usuarios en el censo que se lleve al efecto en el Instituto Nacional de Consumo, para poder obtener las subvenciones, así como la no concurrencia de alguna de las circunstancias previstas en el art. 21 de la Ley 26/1984, de 19 de julio, General para la Defensa de los Consumidores y Usuarios.

a) El primer inciso del citado número es consecuencia del apartado tercero del art. 20 de la Ley 26/1984, en el que se establece la necesidad de la inscripción de las asociaciones de tal carácter para gozar de los beneficios que les otorgue la citada Ley, disposiciones reglamentarias y concordantes, en un libro registro que se llevará en el Ministerio de Sanidad y Consumo.

Pues bien, respecto a esta cuestión, la STC 15/1989 declaró que la obligación de la inscripción de las asociaciones para obtener beneficios no era inconstitucional, sino que opera como una condición previa para dicho otorgamiento "no advirtiéndose en ello condicionamiento ilegítimo alguno para las asociaciones constituidas con arreglo a la normativa propia que, en su caso, pueden dictar las Comunidades Autónomas con competencia en materia de asociaciones y defensa del 
FRANCISCO JAVIER FERNÁNDEZ GONZÁLEZ

consumidor y del usuario". Y por otra parte, dicha carga “...encuentra plena cobertura en las competencias que el Estado ostenta en materia de asociaciones y en las que, respecto de determinadas Comunidades Autónomas, ha retenido también en relación a la defensa de los consumidores y usuarios".

Por consiguiente, la obligación de la inscripción de las Asociaciones de Consumidores y Usuarios en el censo que lleve al efecto el Instituto Nacional de Consumo prevista en el primer inciso del núm. 1 . $^{\circ}$ de la Orden ministerial no implica una invasión por el Estado en la competencia exclusiva que sobre esta materia ostenta la Comunidad impugnante.

b) En cambio, no podemos llegar a la misma conclusión respecto a los restantes números de la Orden ministerial objeto del conflicto, incluyendo el segundo inciso del núm. $1^{\circ}$.

En efecto, tanto las circunstancias reguladas en el art. 21 de la Ley $26 / 1984$, en las que no pueden incurrir las Asociaciones de Consumidores para poder obtener las subvenciones previstas en la Orden ministerial, recogida en el anteriormente citado segundo inciso del núm. $1^{\circ}$, como la determinación de las finalidades específicas a que deben ir destinadas las subvenciones (ap. $3^{\circ}$ ), así como los criterios a ponderar en el reparto de aquéllas (ap. $4^{\circ}$ ). Finalmente, el procedimiento para obtener las mismas (aps. $6 .^{\circ}$ y $7 .^{\circ}$ ) entra de lleno en la competencia exclusiva que ostenta la C.A. de Cataluña en lo referente a las Asociaciones de Consumidores radicadas en su territorio, implicando un exceso competencial por parte del Estado. Pues, de conformidad con la doctrina anteriormente expuesta, al tratarse de una competencia exclusiva de la C.A. recurrente, el Estado debe limitarse a determinar la afectación genérica del destino a que deben dedicarse los fondos presupuestarios en función de materias o sectores de la actividad económica en el caso que nos ocupa en el sector de las Asociaciones de Consumidores radicadas en el territorio de la C.A., pero las finalidades específicas a que deben ir destinadas las subvenciones, así como los requisitos y demás circunstancias sobre su otorgamiento, y la gestión de las mismas es competencia de la mencionado C.A.» (Vid. f. j. 6).

"Hay que tener presente que la citada Orden se refiere a un ejercicio económico ya cerrado y que ha agotado sus efectos, y además, la anulación de los citados preceptos podría suponer perjuicios a aquellas Asociaciones de Consumidores y Usuarios radicadas en la C.A. de Cataluña para el año 1985 a esta Comunidad, con la obligación de la inscripción de las mismas en el censo correspondiente del Instituto Nacional de Consumo, sin necesidad de anular los mencionados preceptos de la Or- 
JURISPRUDENCIA

den, ni menos todavía las subvenciones ya concedidas al amparo de la misma» (vid. f. j. 7).

FALlO: $1 .^{\circ}$ Que el primer inciso del núm. 1 de la Orden ministerial de 29 de marzo de 1985 no invade la competencia de la Comunidad Autónoma.

2. ${ }^{\circ}$ Que el inciso segundo del núm. 1 y los núms. 3, 4, 5, 6 y 7 de la misma Orden invaden la competencia de dicha Comunidad.

(Sentencia $n .^{\circ} 133 / 1992$, de 2 de octubre. BOE 29-10-1992. E. Díaz Eimil).

\section{c) Entidades de crédito}

I. Conflicto positivo de competencia $661 / 1985$ promovido por el Gobierno de la Nación en relación con el Decreto 54/1985, de 4 de julio, del Consejo de Gobierno de la C.A. de Cantabria, sobre cooperativas de crédito. Las cooperativas de crédito y las Cajas de Ahorro presentan una faceta o dimensión de notable importancia en cuanto a la planificación y ordenación económica regional, asi como una dimensión social que les otorga una innegable especificidad que trasciende el título referente a la ordenación del crédito, por lo que no son materias ajenas al ámbito competencial autonómico, lo cual justifica no sólo su inclusión en los Estatutos de todas las Comunidades Autónomas, sino también la abundancia y generalidad de las disposiciones legales y reglamentarias autonómicas referentes a cooperativas de crédito y Cajas de Ahorro. Lo que se plantea no es la incompetencia global de la CA para regular las cooperativas de crédito, sino si se ha incidido en materias no asumidas por la misma a través de su Estatuto.

"La Comunidad Autónoma de Cantabria...ha asumido competencias, aunque no de carácter exclusivo, "de acuerdo con las bases y ordenamiento de la actuación económica general y la política económica del Estado" sobre "instituciones de crédito corporativo, público, territorial y Cajas de Ahorro" (art. 28.2 EA Cant.), cuyo ejercicio no se condiciona a transcurso de plazo o ampliación de competencia alguna. Esta asunción competencial encaja sin dificultad en la habilitación constitucional del art. $148 \mathrm{CE}$ a las Comunidades Autónomas para que incluyan en sus Estatutos competencias en materia de "fomento del desarrollo económico" (art. 148.1.13) y se relaciona estrechamente con las competencias de Cantabria en orden al "fomento del desarrollo económico de la CA" (art. 22.1. EA Cant.), "planificación de la actividad económica de Cantabria" (art. 28.1 EA Cant.) y "sector público-econó- 
mico de Cantabria" (art. 28.3). A ello habrían de añadirse las previsiones de fomento de sociedades cooperativas del art. 56.4 del Estatuto.

En efecto, junto a los aspectos laborales mercantiles y de ordenación del crédito puestos de manifiesto por el Abogado del Estado, resulta innegable que las instituciones de crédito corporativo, público y territorial, así como las Cajas de Ahorro, presentan una faceta o dimensión de notable importancia en cuanto a la planificación y ordenación económica regional, así como una dimensión social que...otorga a estas instituciones una innegable especificidad que trasciende el título referente a la ordenación del crédito. Por consiguiente, las cooperativas de crédito y las Cajas de Ahorros no son materia en absoluto ajenas al ámbito competencial autonómico, lo que justifica, no sólo su inclusión en los Estatutos de todas las Comunidades Autónomas, sino también la abundancia y generalidad de las disposiciones legales y reglamentarias autonómicas referentes a cooperativas de crédito y Cajas de Ahorro. No cabe por ello estimar que exista una "incompetencia global" de la CA de Cantabria para dictar regulaciones en materia de cooperativas de crédito" (vid. f. j. 2).

"La cuestión se plantea, pues, no en cuanto a la incompetencia global de la CA para regular las cooperativas de crédito, sino en cuanto al segundo tipo de motivos aducido por el Abogado del Estado, esto es, si se ha incidido en materias no asumidas por la misma a través de su Estatuto. Ello conduce a un análisis de los diversos artículos del Decreto cántabro en relación con las competencias estatales que el Abogado del Estado estima vulneradas, es decir, la ordenación del crédito y la coordinación de la planificación económica.

En el ejercicio de estas competencias, el Estado, con posterioridad al planteamiento del presente conflicto, ha dictado diversas disposiciones que integran en este momento la ordenación de las entidades de crédito y que, de acuerdo con reiterada doctrina de este Tribunal...han de servir como criterio inicial para determinar el ámbito de las respectivas competencias del Estado y de la CA en esta materia y, consiguientemente, para la resolución del contencioso planteado. Estas disposiciones son, esencialmente, el Real Decreto Legislativo 1298/1986, de 28 de junio, de adaptación del derecho vigente en materia de Entidades de crédito al de las Comunidades Europeas, la Ley 26/1988, de 29 de julio, de Disciplina e Intervención de Entidades de Crédito, y, finalmente la Ley 13/1989, de 26 de mayo, de normas reguladoras de Cooperativas de Crédito...Puesto que la CA de Cantabria no ha asumido competencias relativas a la ordenación del crédito (por quedar fuera de la enumeración contenida en el art. $148 \mathrm{CE}$ ), deberá tomarse como punto de referencia para determinar la adecuación competencial de los artículos que 
JURISPRUDENCIA

se impugnan del Decreto cántabro la integridad de las disposiciones citadas, independientemente de que se consideren o no sus mandatos como básicos.

El art. 1 del Decreto se limita a indicar que la CA de Cantabria asume "cuantas competencias, de acuerdo con la Constitución Española y el EA de Cantabria, le corresponden" en relación con las Cooperativas de Crédito, según las normas en el momento vigentes. Nada puede reprocharse a una declaración de este tipo, que expresamente se remite a los límites competenciales constitucionales y estatutarios.

El art. 2 lleva a cabo una definición de que debe entenderse por Cooperativas de Crédito. Ahora bien, siendo esas cooperativas instituciones de crédito, tal definición, en cuanto acota la materia a regular y sirve así como elemento esencial delimitador de competencias, resulta sin duda aspecto esencial de la ordenación del crédito y, de hecho, el art. 1 de la Ley 13/1989, lleva a cabo esta definición. Ha de concluirse, pues, que el art. 2 del Decreto vulnera el orden competencial, debiendo la CA atenerse, en la determinación de que sea una Cooperativa de Crédito, a la normativa estatal.

El art. 3 determina en su primer párrafo que será preceptiva la inscripción de las cooperativas de crédito en un Registros especial de la CA, "sin perjuicio de su inscripción en los registros de ámbito nacional”. No puede considerarse que esta previsión vulnere el orden competencial al salvarse en todo caso la inscripción en los Registros estatales, sin que la inscripción en el Registro autonómico impida o dificulte el ejercicio de las competencias del Estado de ordenación del crédito siendo por el contrario elemento facilitador del ejercicio de competencias autonómicas en materia de fomento y de planificación económica.

El párrafo segundo del mismo artículo atribuye la autorización para la creación de cooperativas de crédito al Consejo de Gobierno de la CA de Cantabria. Esta previsión contradice la del art. 5.1 de la Ley 13/1989 (disposición final segunda), que establece que "la constitución de una Cooperativa de Crédito requerirá autorización previa del Ministerio de Economía y Hacienda". Por tanto, debe concluirse que la disposición del párrafo segundo del art. 3 del Decreto controvertido, en cuanto desconoce la competencia estatal, vulnera el orden competencial.

El art. 4 atribuye a la CA funciones de "inspección, control e intervención", salvándose la competencia al respecto del Banco de España. Esta última circunstancia permite considerar que el precepto en cuestión no invade competencia estatal alguna, pues quedan en cualquier caso sin afectar las potestades de inspección estatales. Por otra parte, el 
que la CA disponga de competencias en materia de cooperativas de crédito supone, como potestad inherente, la de verificar si se cumplen las correspondientes disposiciones autonómicas.

El art. 5 del $\mathrm{RD}$ prevé que la CA disponga de potestad sancionadora respecto de las cooperativas de crédito. A este respecto, y en relación con la potestad sancionadora en general, la Ley $26 / 1988$ de disciplina e intervención de entidades de crédito admite (art. 42) que las Comunidades Autónomas dispongan de esa potestad. Más reveladoramente, el art. 42.1 prevé que la declaración de básicos de determinados preceptos en materia sancionadora "se entiende sin perjuicio, en su caso, de la posiblidad de tipificación por las Comunidades Autónomas, como muy graves, graves o leves, de otras infracciones de sus propias normas en materia de ordenación y disciplina". Ahora bien, esa admisión se realiza, de acuerdo con las normas de la misma ley, con una serie de matizaciones y excepciones, quedando, en determinados supuestos, reservada a órganos estatales la potestad sancionadora. En cuanto la norma cántabra, en su art. 5, tiene carácter general y no especifica previsiones de carácter sancionador referidas a supuestos reservados al Estado, no cabe estimar que resulte contraria al reparto constitucional y estatutario de competencias. Esta determinación normativa no queda, por tanto, fuera de las competencias autonómicas, entendida, no como una sustitución de la potestad sancionatoria reservada al Estado, sino como la capacidad de tipificar y sancionar las infracciones de sus propias normas. La remisión que el art. 5 establece a la normativa estatal viene a salvar la reserva en favor del Estado en esta materia.

El art. 6 prevé la obligación de comunicar al Consejo de Gobierno el nombramiento de Director general o asimilado, las modificaciones de sus Estatutos, los presupuestos para cada futura anualidad junto con la correspondiente memoria explicativa y, finalmente, la fecha y cuantía de las cantidades recibidas de entidades de carácter nacional para otorgar préstamos a sus asociados. Se trata de una obligación que se corresponde con las competencias de la CA, tanto en la planificación y el fomento de la actividad económica, y sin que ello suponga dificultad o impedimento para el ejercicio de las competencias estatales de ordenación del crédito. Así pues, procede concluir que con esta disposición no se vulnera en forma alguna el reparto constitucional y estatutario de competencias.

El art. 7 establece la posibilidad de que el Consejo de Gobierno designe "a la persona o personas que sustituyen a los órganos rectores con suspensión de las funciones de los mismos" a fin de que se convoque una asamblea general que designe nuevos órganos rectores. Esta potestad de intervención -que se justifica en situaciones excepcionales 
que afecten a los socios, o a la economía nacional- aparece claramente diseñada para salvaguardar la solvencia de las entidades de crédito en cuestión y, en consecuencia estrechamente vinculada a la ordenación del crédito, competencia estatal. A este respecto, el título III de la Ley de disciplina e intervención de entidades de crédito, bajo el epígrafe "Medidas de intervención y de sustitución" establece en su art. 31.1 que "únicamente cuando una entidad de crédito se encuentre en situaciones de excepcional gravedad que ponga en peligro la efectividad de sus recursos propios o su estabilidad, liquidez, solvencia, podrá acordarse la intervención de la misma o la institución provisional de sus órganos de administración o dirección". Esta medidas (art. 32.1) "se acordarán por el Banco de España, dando cuenta razonada de su adopción al Ministerio de Economía y Hacienda". Se desprende de ello que se trata de una facultad incluida en la competencia estatal en materia de crédito y coordinación de la planificación económica y, por ello, fuera del ámbito competencial de la CA.

Finalmente, el art. 8 del Decreto atribuye a la Consejería de Economía de la CA de Cantabria la "declaración de descalificación" de las cooperativas, término que debe entenderse equivalente al de "revocación de la autorización" utilizado por la Ley estatal 26/1988 y que ésta prevé como una de las posibles sanciones para las infracciones muy graves (art. 9b). Esta atribución excede de las competencias que esta CA puede asumir en materia de cooperativas de crédito. En efecto, el art. 4 de la citada Ley contiene las infracciones calificadas como muy graves, siendo las mismas infracciones relativas a la ordenación del crédito, con lo que excederían los límites dentro de los cuales esta CA ha podido asumir competencias sobre cooperativas de crédito, en los términos más arriba expuestos» (vid f. j. 3).

FALLO: $1 .^{\circ}$ Declarar que los arts. 2, 3, párrafo segundo, 7 y 8, del Decreto 54/1985, de 4 de julio, de la CA de Cantabria invaden la competencia estatal, y son por consiguiente nulos.

2. Desestimar el conflicto de competencia en todo lo demás.

(Sentencia $n .^{\circ} 134 / 1992$, de 5 de octubre. BOE 29-10-1992. P. Cruz Villalón).

II. Recursos de inconstitucionalidad 800 y 801/1985 (acumulados), promovidos por el Consejo Ejecutivo de la Generalidad de Cataluña y el Gobierno Vasco, respectivamente, contra determinados preceptos de la Ley 13/1985, de 25 de mayo, sobre coeficientes de inversión, recursos propios y obligaciones de información de los intermediarios financieros. 
«En el esquema constitucional de la distribución territorial de competencias, una de las que se entrega al Estado con carácter exclusivo tiene por objeto las "bases de la ordenación" del crédito y de la banca (art. 149.1.11 ${ }^{\mathrm{a}}$ ). Esta atribución, no obstante la ambigüedad o insuficiencia de la exclusividad como característica delimitadora, prefigura la materia respecto de la cual se ejerce pero no la forma a través de la cual han de ser desarrolladas las distintas potestades implícitas en el enunciado. Por lo tanto, tampoco indica la institución o el órgano encargado en cada caso y momento de sentar esos cimientos de la regulación. Esto es lo que, en definitiva, significa la proposición de que el concepto de "bases" ha de ser entendido aquí y ahora, dentro de esta concreta competencia, en su acepción material según se dice en nuestra STC 1/1982 (...) Es evidente que la Ley 13/1985, de 25 de mayo, ahora en tela de juicio, encaja por su contenido material en la ordenación del crédito y la banca, no ya porque así lo afirme en su preámbulo, sino porque esa declaración del legislador responde a la realidad, y en tal aspecto no ha sido puesta en duda por quienes la impugnan en este proceso. En efecto, este Tribunal Constitucional ha tenido ocasión de perfilar el contenido sustancial de esa competencia estatal exclusiva, cuyas bases "deben contener tanto las normas reguladoras de la estructura, organización interna y funcionamiento de los diferentes intermediarios financieros como aquéllas otras que regulen aspectos fundamentales de la actividad de tales intermediarios, entre los cuales se insertan legalmente las Cajas de Ahorro". Aquí tienen su asiento propio las disposiciones consistentes en fijar ciertos porcentajes o coeficientes obligatorios sobre los recursos ajenos depositados en las Cajas que deben invertir éstas en la adquisición de fondos públicos, así como también las que determinen cuáles son los valores públicos cuya adquisición por las Cajas se considera computable para cubrir el citado coeficiente de fondos públicos y también el orden de prioridades de esas inversiones obligatorias» (vid. f. j. 1).

"Estas "bases" han de ser, en principio, normas legales, orgánicas rara vez y ordinarias en su mayor parte, pero también, en su caso, reglamentarias, en el uso de la potestad que al Gobierno de la Nación otorga el art. 97 de la Constitución. En tal línea de actuación, el título I de la Ley 13/1985 fue objeto del correspondiente desarrollo por el RD $2254 / 1985$, de 20 de noviembre, mientras que el art. 6, con el cual se inicia el título II, había provocado la promulgación de otro RD, el 1370/1985, de 1 de agosto, donde se establece el nivel mínimo a alcanzar por los recursos propios de las diferentes entidades de depósito y los criterios para su cómputo. Por otra parte, y bajando un escalón más en la jerarquía normativa, hay una serie de disposiciones o "medidas" que concretan elementos en blanco de la norma legal para permitir su adaptación a las circunstancias y, por ello, participan de esa misma na- 
JURISPRUDENCIA

turaleza normativa. En efecto, la estructura como un todo no puede olvidar los aspectos coyunturales y más en este ámbito de la economía. Por ello, tales actuaciones son desarrollo reglamentario, también básico, de la Ley en la cual encuentra cobertura específica esta deslegalización mediante la doble técnica de autorizar una eventual delegación del titular originario de la potestad o atribuirla directamente al Banco de España, institución cuyo carácter "básico" ha sido puesto de relieve en nuestra STC 1/1982 (...) El Banco de España forma parte de la Administración del Estado en su vertiente institucional o indirecta y es la primera autoridad monetaria, a quien corresponden las funciones relativas a la disciplina e inspección de las entidades de crédito y ahorro, para lo cual se le dota de las simétricas potestades, entre las cuales deben destacarse la reglamentaria y la sancionadora, como pone de manifiesto la atenta lectura de la Ley 30/1980, de 21 de julio (arts. 1; 3; 15.1, 9 y 10, y 16.7) (...) La ordenación básica del crédito y la Banca, en su aspecto institucional, corresponde no sólo a los Cuerpos colegisladores y al Gobierno, sino también, en un nivel operativo, al Banco de España» (vid. f. j. 3).

"El contenido esencialmente normativo de las "bases" para la regulación del crédito y la banca...no significa que en esa "ordenación" no quepa otro tipo de actuaciones. Aun cuando, en principio, la aplicación de la norma a cada supuesto de hecho individualizado parece estar extramuros de aquélla, también pueden quedar comprendidos en su ámbito los actos ejecutivos, actos administrativos singulares en cuanto resulten necesarios para la preservación de lo básico o para garantizar, con carácter complementario, la consecución de los fines inherentes a la regulación básica. Esta posibilidad de pasar a la ejecución tiene su fundamento no sólo en las exigencias de la unidad del sistema económico general, lo que se ha llamado la "constitución económica", para cuya intangibilidad no bastan los denominadores comunes de naturaleza normativa, sino también en la necesidad de actuaciones estatales directas por razones de urgencia en prevención de perjuicios irreversibles al interés general. En definitiva, las competencias para el desarrollo legislativo o la ejecución de las Comunidades quedan vinculadas a una política monetaria y crediticia general que no es solamente susceptible de ser establecida por vía normativa» (vid. f. j. 5).

FALLO: Desestimar los recursos de inconstitucionalidad.

(Sentencia $n .^{\circ} 135 / 1992$, de 5 de octubre. BOE 29-10-1992. R. de Mendizábal Allende). 
